\title{
Responsibility-driven collective action in the context of rapid rural depopulation
}

(i) The corrections made in this section will be reviewed and approved by a journal production editor.

Pingyang Liu Writing - original draft Methodology Conceptualization ${ }^{\mathrm{a}, \mathrm{b}}$ pyliu@fudan.edu.cn, Ye Zhao Writing - original draft Investigation a,b 18210740072@fudan.edu.cn, Neil Ravenscroft Writing - review \& editing Formal analysis ${ }^{c}$ Neil.Ravenscroft@rau.ac.uk, Marie K. Harder Writing - review \& editing Formal analysis a,d,* M.K.Harder@brighton.ac.uk

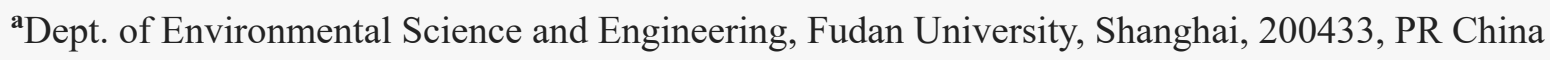

${ }^{\mathbf{b}}$ Center for Land and Resource Economics Studies, Fudan University, Shanghai, 200433, PR China

'School of Real Estate and Land Management, Royal Agricultural University, Gloucestershire, GL7 6JS, UK

${ }^{\mathbf{d}}$ School of Computing, Engineering and Mathematics, University of Brighton, BN2 4GJ, UK

*Corresponding author. Dept. of Environmental Science and Engineering, Fudan University, Shanghai, 200433, PR China.

\section{Abstract}

China has witnessed unprecedented and rapid urbanization which has led to the depopulation and structural collapse of many traditional rural village communities, and the decline of many collective functions such as the effective management of the public realm. In seeking to address this problem it is clear from the literature that there is considerable potential in catalyzing collective action, particularly where there is a moral imperative to act and the availability of leaders with the ability to organize the collective. However, while there is evidence that community-based collective action has provided effective localized solution pathways for managing collective goods when the focus has been on the distribution of benefits, there is little evidence about its potential in scenarios associated with the distribution of costs, or responsibilities. In addressing this asymmetry, we present a case study of a typical village near Shanghai which has successfully established a community based environmental management system, and describe the process, characteristics and influencing factors of its responsibility-centered collective action. Our findings show that smart 
local leadership, an effective organizing strategy, and involvement of a suitable 'core group' was crucial. The strategy of mobilizing this core group, of empowering them with decision-making rights, and supporting their volunteered role as a 'bridge and platform' connecting the village cadres and villagers, significantly reduced the enforcement and monitoring costs, controlled free rider problems, and gained public support and participation, leading to a stable and sustainable solution. Our findings illustrate specific principles that apply to many cases in China, and general principles that are likely to be applicable more widely.

Keywords: Distribution of responsibility; Rural depopulation; Collective action; Rural environmental management; Elderly party member

\section{Introduction}

China has been in the process of rapid urbanization for many years, accompanied by a spatio-temporal ruralurban migration (Wang et al., 2016) which has led to continuous significant depopulation, economic stagnation and structural changes in rural areas (Carr and Kefalas, 2009; Long et al., 2011; Kan, 2016; Liu and Li, 2017), including the decline of collectively-organised public services [Instruction: please delete the following words: "such as road and bridge maintenance".]such as road and bridge maintenance (Liu and Ravenscroft, 2016, 2017). Despite considerable efforts to support rural development (Long et al., 2011; Li et al., 2011), many villages continue to suffer from serious environmental degradation, aging populations, and insufficient infrastructure and public services. In this context, environmental management in these villages has become a critical challenge for China's rural sustainable development.

Part of the problem is that rural environmental management is a type of regional public good (Mccarthy and Kilic, 2015) that involves a multitude of stakeholders as well as the distribution of benefits and responsibilities among them. In China, in the context of rapid urbanization and rural depopulation, the mechanisms for the maintenance of such village level public goods has collapsed leaving a situation where stakeholders fight for benefits as well as seeking to escape their responsibilities, leading to the failure of effective environmental management. Normally, in China and elsewhere, environmental management problems in villages are dealt with via state action, often regulated nationally and implemented locally, or via the purchase of services through [Instruction: please replace "conventional market mechanisms" with "kinds of market mechanisms".] conventional market mechanisms (Coase, 1960; Hardin, 1968; Olson, 1965). However, both of these approaches are hindered by inefficiency and high costs of monitoring and enforcement, and often from a lack of sufficient local expertise. These issues are reported to be even more serious when rural environmental management has been intertemporal and cross-regional (Kapoor, 2001; Dietz et al., 2003).

Theoretical and empirical research by Ostrom (1990) and other scholars has elaborated a third way of tackling rural problems including environmental management. Community-based collective action, when organized effectively, has been proven to be successful in dealing with the management of rural public goods, or common pool resources (Ostrom, 1990; Agrawal, 2001; Saunders et al., 2014). Examples include the sustainable management of collective forests (Liu and Ravenscroft, 2016), construction and maintenance of 
irrigation systems (Takayama et al., 2018), and optimization of collective construction land (Liu and Ravenscroft, 2017).

Such findings are consistent with the history of rural governance in many countries. For example, traditionally, rural communities in China were acquaintance-based societies dominated by geographical relations and blood relations, with the typical function of helping and supporting each other; they were governed by their own village rules and led by village elites who themselves had common concerns and a shared context ( Feuchtwang, 1998). Thus even without government intervention and investment, communities managed to organize village level public goods, such as the maintenance of roads and bridges, construction and management of farmland irrigation systems, and keeping the village clean, tidy, sanitary and looking beautiful. However, whether such collective action is likely to continue under conditions of rapid urbanization and rural depopulation remains unclear. A key challenge is the impact of large-scale rural depopulation and the disempowerment of the 'left-behind' elderly population. These rapidly changing and un-stable conditions have led to the replacement of the fundamental relationship connections (renqing) by economic relations instead ( Liu et al., 2016). The Village Committees, which used to be autonomous organizations, have gradually become extensions of government administrative systems (Liu and Xiong, 2018), and the villagers' sense of belonging to any collective has been eroded.

Such conditions violate the preconditions of Ostrom's (2000) requirements for effective collective action, such as the stability of community, effective governance mechanisms, and an abundance of knowledge and skills. Additionally, the public goods in this case require distribution of responsibilities on the part of the collective, which provides a challenging arena in which to foster collective action in which there is no imminent prospect of individual benefit or reward. This is in contrast to the many reported cases concerning the distribution of benefits (Ostrom, 2000) connected with common pool resources such as community forests (eg: Liu and Ravenscroft, 2016; Persson and Prowse, 2017), fisheries (eg: Sultanaa and Abeyasekera, 2008) and irrigation systems (eg: Takayama et al., 2018).

In this paper, therefore, we want to introduce a new concept, of responsibility-driven collective action, as a social process that is founded in care for the collective rather than in the expectation of individual pecuniary benefit. Using a case study of a village in China, we seek to examine how such an approach might work in the situation where the individuals in the collective have to assume financial and personal responsibility for a programme of work that offers little possibility of future rewards beyond mutual care for the village and its people. In pursuing this work we have been guided by the following research question:[Instruction: please delelte the punctuation between ": "and "To".] 'To what extent can a new form of responsibility-driven collective action provide a solution to the under-provision of public goods? In addressing this question we believe that this study can contribute to an enhanced understanding of collective action in the context of rapid urbanization and rural depopulation, as well as having potential use in studying the distribution of responsibilities in marginalized rural communities.

\section{Literature review}

According to Ostrom (2002), collective action is in essence the performance of the provision of collective, or public, goods. And the capacity for collective action of a community is regarded as the key for the wider goal 
of successful transformation and sustainable development (Beard and Dasgupta, 2006). Research on community-level collective action has been carried out with respect to a wide range of issues including community forestry management, fishery, and irrigation, but why and how collective action happens, is mobilized and achieved success, remains unclear, particularly where there is no immediate prospect of the distribution of individual (pecuniary) benefits to those involved.

A widely cited argument of Van Zomeren et al. (2008) is that collective action is based on the three sociopsychological perspectives of perceived injustice, efficacy and identity. Perceived social injustice, and any subsequent relative deprivation, has been conceptually regarded as a fuse for igniting collective action. However, empirical studies have shown that such connections are weak (van Zomeren et al., 2012), and that there is little prospect of communities feeling strong social injustice if the issue is, for example, the maintenance of their roads and bridges. Thus, conventionally the emphasis of collective action has been on the other motivating factors, particularly efficacy. Yet in few cases in rural communities in China have those remaining after depopulation stood up for their rights, even where it would be justifiable to have done so (Du et al., 2019). The socio-psychological explanation for this lack of action is that villagers have tended to make their decisions about whether to engage or not on the basis of their perception of others' action. This type of collective efficacy has been found in social movement scenarios such as pro-environmental and anti-war movements (Chan, 2016; Thomas et al., 2016; Saab et al., 2015), but empirical examples at the rural community level are rare. Indeed, as Sandler (2015) has argued, cost-benefit considerations are often more significant than efficacy itself, with decisions often hinging on individual utility and cost functions. Lastly, the social identity of participants may contribute to the initiation and mobilization of collective action: when people have a strong common identity, such as the same career or blood relationship, they are more willing to fight for their common interests (Thomas et al., 2016). This strand of explanation is likely to be relevant to the case of a Chinese village, although the sense of belonging is now quite weak in many villages after the disruption of village structures due to depopulation (Du et al., 2019).

As this suggests, current research on collective action at the rural community level can be considered as two types. The first is the widely reported collective action as a solution for managing collective resources. Based on Ostrom's (2000) common pool resource governance theory, community based collective action tends to be most efficient for managing collective resources such as forestry, fisheries, and construction land. The motivating factor in many of these cases is that participants in the action stand to gain financially, via the distribution of collective property rights to households or individuals (Liu and Ravenscroft, 2016), or via improved collective and private market performance (Orsi et al., 2017). In such cases it is relatively easy to understand how social injustice can become a cypher that motivates action, particularly if outside interests are seeking to divert resources away from the collective. This situation lends itself to organization and mobilization, especially where there is an existing governance framework that underpins the efficacy of taking action.

The second type of collective action, much less reported and discussed, is about the provision of community level public goods, and is associated with the distribution of responsibilities. We have termed this responsibility-driven collective action. Rural degradation in the process of urbanization is a global trend, and the failure of local governments to maintain public goods, such as environmental pollution treatment, waste 
disposal and village landscape maintenance, is a direct and obvious challenge (Liu and Li, 2017). However, evidence suggests that collective action in these cases rarely happens, even in areas where the community had previously provided their own village-level public goods (Liu and Ravenscroft, 2017). Both benefits and costs are nonexclusive, which leads to the situation that the costs of non-action are shared (i.e. declining public services) while the benefits of action are not pecuniary and do not accrue solely to those taking the action. From the perspective of an individual, therefore, the best choice is not to participate in such responsibilitydriven collective action.

Hence, the motivation and mobilization of collective action of the second type is much more challenging, and there is little evidence in the literature of what it actually is and how it might proceed. Theoretically at least, a trigger is still required to inspire people sufficiently that they reach the "tipping point" that causes them to participate in action (Baldez, 2002). Given the lack of immediate and direct private economic benefits, it has been suggested that other motivating forces are required, such as strong local leadership with the capacity to organize and set up rules, and potentially long term enforcement mechanisms that will ensure the legacy of the action (Meinzen-Dick et al., 2002).

Leadership as a concept in collective action has received increasing attention in the literature, but its application in the field is rare (Glowacki and Von Rueden, 2015). Theoretically, leaders play a primary role in the establishment of goals, setting up rules, monitoring impacts, dispute resolution, and the allocation of rewards and punishments. It has been argued that effective leadership helps improve collective action by reducing the time to consensus and increasing the speed and flexibility of group action (Tooby et al., 2006), as well as improving group performance by facilitating the development of goals and an action plan (Pescosolido, 2001). However, poor leadership can actually undermine the potential for collective action (Anderson and Brown, 2010), by failing to gain trust of others. The concept of a strategy of organizing, including motivation, mobilization and enforcement, is also critical and widely regarded as key to solving the challenges of collective action (Bimber et al., 2012). This refers to the ability to build capacity to support ongoing and sustained change (Ganz, 2002). There are limited empirical examples of the processes of organizing in collective action beyond the early stages of motivation and mobilization, and they are predominantly concerned with distribution of goods rather than responsibilities.

There is also work that emphasizes the significance of the participant's characteristics in achieving collective actions (Ito, 2012). It is generally the case that small groups are regarded as having more potential to provide successful collective goods than large ones (Agrawal, 2003), because of higher private returns and lower costs of communicating and marginalizing free riders (Fałkowski et al., 2017). Research also shows that the degree of heterogeneity among rural villagers is relevant: if the elite members are homogenous as a group, with their goals aligned, there is a greater potential for successful collective action (Vedeld, 2000). In Chinese village society the elites tend to be at the core of a complex network of interests, and are the most likely villagers to be able to act effectively as organizers and activists. Research in developing countries such as India and China indicate that the characteristics of village groups are also quite important, especially those with strong clan traditions. Even the vulnerable groups, such as left-behind women in hollowing out villages, when empowered, show a strong capacity for self-organization and collective action (Du et al., 2019). 
In summary, most research on the motivating forces for collective action are associated with the distribution of benefits, making the mobilization of participants relatively straightforward. In contrast, little is known about the situation that occurs when collective action involves the distribution of responsibilities or obligations among group members. This is clearly a gap in the literature in terms of understanding both the conditions under which collective action is likely to take place, and the extent to which there is a genuine alternative to government action to provide and maintain public goods. This leads us to refine our research question: [Instruction: please delete the apostrophe before "To".]'To what extent does responsibility-driven collective action exist as a distinct and viable approach to the provision of public goods? In addressing this question, we will use a case study of a rural community in China that has dealt successfully with the management of public goods related to landscape and public health in a manner that we can recognize as a particular form of collective action. By understanding how the process of collective action was motivated, mobilized and enforced, we want to identify potentially transferable elements which might help with such increasingly common issues in the widespread context of rapid urbanization, both in China and globally, and to make a contribution to broader considerations about the theory and practice of collective action.

\section{Methodology}

A single case study approach was used, due to the rarity of finding an example of a local resolution to the problem of galvanizing responsibility-driven collective action. This is because most rural communities in China have traditionally relied on direct public investment or publicly funded private services secured through contract markets. Located about $60 \mathrm{~km}$ southwest of Shanghai, Xulian Village in QingPu District is a typical village arising from the merging of two formerly independent rural communities. The village covers 2.02 square kilometers, with 1602 villagers living in 631 households. Economic development at Xulian Village has lagged behind many neighbouring villages, with annual farm incomes in the region of 25,000 RMB per capita in 2018. This is approximately $82 \%$ of the average income level for the rural areas of Shanghai and less than $40 \%$ of average incomes for Shanghai as a whole. The village has an elected Village Committee of five persons and a Party Branch containing all the Party members in the village ( 73 persons in this case) which is led by the Party Secretary who is elected by the Party Branch and appointed by the Township Committee. The power for all village decisions ultimately lies with the Secretary of Party Branch, but in principle there are eight village cadres, drawn from the Village Committee and the Party Branch, who could act as a decisionmaking group with the Secretary. The influence and power of the eight cadres varies from village to village, with the previous Secretary of Xulian Village generally making decisions unilaterally. In contrast, the current Secretary chooses to involve them in significant decisions.

Although relatively close to Shanghai, Xulian Village has witnessed the loss of most of its younger generation, who have migrated to the city in search of work. This means that only the elderly, mothers and children are left in the village. This is a common situation in rural China, regardless of how close villages are to the cities (Du et al., 2019). The village has also faced significant environmental problems such as river encroachment and water pollution, illegal building development spoiling the quality of the landscape, sanitary waste dumping and unregulated poultry farming. In the past, the local government has invested considerable funds on the construction of wastewater facilities, village cleaning and waste disposal, but the top down input without villagers' involvement failed due to lack of maintenance and monitoring, as well as villagers' unwilling to 
changing their pollution behaviors. Little progress had been made at that time. [Instruction: Please delete this sentence:

"This has led to the cessation of public funding."]This has led to the cessation of public funding.

Things began to change in 2014, when a new Secretary of the village was appointed, who managed to initiate and mobilize the whole village to participate in the remediation of the environmental problems and the beautification of the village. In particular, the village successfully accomplished the demolition of all the illegal buildings without repercussions, kept all unsanitary areas clean, controlled informal poultry breeding and carried out remediation of the village river. Through collective action, the village environment was significantly improved, and Xulian was awarded the title of 'Beautiful Village of Shanghai' in 2017. In addition, Xulian continued its collective action to develop a long-term Beautiful Village Plan. This has gained support from the local government, because the village now meets all kinds of regulations. The plan also enjoys the support of the villagers (as they recognize that they all benefit from an improving environment that provides new opportunities for the development of new economic activity, such as tourism); and of the collective (because the community is getting stronger). Ultimately, Xulian Village seems to have demonstrated the potential of responsibility-driven collective action despite suffering from rural depopulation and having to cope with difficult issues around the need for financial contribution from those who have been left behind.

On-site investigations were undertaken in the village from April to December 2018, with a supplementary investigation in December 2019 that was used to clarify ambiguous information. Semi-structured interviews were carried out with key informants to gain detailed information about the processes that had occurred. Key informants were identified as we became more familiar with the roles played. We started with the Secretary of Party Branch (hereinafter called Secretary) who played the central role.

From the Secretary, we learned that the elderly Party members had volunteered very early in the process to do significant mobilization and monitoring work. In particular, there were three who operated a drop-in 'service station' in their own houses, each assisted by another two old Party members, where anyone could drop in to talk about their concerns and how these might be addressed. These elders referred to their work as 'bridging the village leaders and the villagers', so we chose two leader types (one Village Committee leader, and one village cadre) as key informants for interviews. In addition, we held semi-structured interviews in the village with 10 villagers and 2 incomers. The participants were selected by the interviewers on a 'next available person' basis. Interview schedules were constructed around conceptual processes of collective action, the formulation of rules, the mobilization strategies applied, difficulties encountered, efforts in finding solutions, and the final outcomes of the collective action. In addition, focus group discussions were held twice with a group comprising the village Secretary, village cadres, and highly respected elderly Party members, focusing on changes in the village before and after the collective action, the motives and main problems, and ideas of further improvements. Finally, in order to obtain a comprehensive understanding of the collective action, participant observations were carried out. Two researchers stayed in the village for four days, observing the elderly Party members patrolling the village, negotiating with villagers, and discussing issues with the village cadres. We also attended the weekly gathering of Party members who were discussing and undertaking volunteer jobs in the village. In addition, we wandered around the village to watch villagers' normal activities as well as to check the status of the maintenance of the village environment. 
All interviews and onsite observations were written down in shorthand, and complete transcripts were written up the same evening. They were later translated into English. We also obtained records of issues raised and subsequent actions from the three service stations, and documents from township governments and the village. All these data were analyzed and interpreted by deep reading in order to generate a picture of how the collective action took place, matured to a functional level, and succeeded in resolving internal and external problems.

\section{Findings}

The research commenced from a desire to examine how collective action might be galvanized where it has previously struggled. The literature indicates that this is most unlikely to occur where there is no immediate prospect of individual benefits and no imminent and otherwise irrefutable danger to the community. In such cases the free-rider phenomenon arises, where some members of the collective refuse to join the action because they know that they will gain any eventual benefit without contributing to the cost of achieving it. This constrains the ability of the leaders to build a good connection with the collective, and can undermine the success of the action itself. The case of Xulian Village offers a different narrative, as set out in the following subsections, each of which is framed around the common failures of conventional collective action.

\subsection{The muted injustice of the failure to maintain the supply of village level public goods}

Xulian Village is the epitome of rural decline in the process of urbanization in China (Li et al., 2016), facing challenges of depopulation and aging, collapse of traditional community and a sluggish local economy. As a result, the village depends to a large extent on sustained government investment to provide village-level public goods. For example, local government agencies were solely responsible for the maintenance of the village environment, including the construction of domestic wastewater treatment facilities, as well as employing two workers to keep the village clean and tidy. Nevertheless, the village remained in a dirty, chaotic and poor condition, which was largely accepted by those left behind after depopulation. The lack of regulation and attention allowed some public spaces to be gradually encroached upon by illegal construction activity. Trash was dumped into corners and rivers, while people directly discharged sanitary waste into nearby rivers rather than using the appropriate facilities. Excrement from free ranging chickens and ducks was everywhere, resulting in a bad odor and many mosquitoes. This led one Party member to comment that:

"In the past, the roads in the village were uneven (due to dumped waste), even though there were garbage cans (provided), the villagers still dumped rubbish at random. The droppings of chickens and ducks raised by the villagers were all over the road: we could hardly walk. The riverside was full of chicken and duck sheds which was undesirable and looked awful." (Xu D, male, elderly Party member)

Even though villagers and village cadres both complained about the environmental problems, neither thought it was their responsibility. The villagers claimed that the village cadres did not carry out their duties, while the village cadres criticized the poor attitudes of the villagers, which to them indicated that nobody regarded the community as their common inheritance, or fortune. The village thus became divided by personal political and economic issues, increasingly driven by the maximization of private interests. 
In 2014, a native villager returned to the village as the new Party Secretary. She concluded that the core of the problem lay in the dysfunctional Village Committee and Party Branch, and that without the effective organization of the villagers, no work could be carried out.

"(In the past) our Committee was disunited. The Party members and cadres had poor organizational discipline, and they did not provide leadership, which led to the villagers and Party members being not of one mind." (Shen, female, village Secretary)

In rural China, Party members are a special group. They are usually people who have received a good training or education, with high skills or good prestige. In the era of the Collective Economy, Party members played a pioneering, core and exemplary role in the face of all kinds of difficulties; they were very much the cornerstone of village-level autonomy. However, this declined after the Reform and Opening Up Policy, along with the collapse of traditional community mechanisms and administrative control of Village Committees, the system of collective learning and discussion, and decision-making by minority obeying majority in the village branch, were abandoned, to a position where power had been concentrated in the former Secretary.

"The former village Secretary and the village director couldn't get together. The Party member meetings might occur only 2-3 times a year, or even not at all. If things came up, he (village Secretary) had the final say." (Xu D, male, elderly Party member)

Under these circumstances, the Village Committee and village cadres lost their prestige and became pariahs in the eyes of the villagers. The villagers could not participate in, and were not even informed of, important decisions, and thus became disinterested in contributing to the future of the village, and centered around their personal benefits. Whenever their benefits were compromised, they were likely to go and quarrel with the village cadres in their office.

\subsection{Establishing the efficacy to work for change}

By the time that the new Secretary took office there was a big opportunity for the village: [Instruction: Please replace "QingPu" with "Qingpu".]QingPu District had adjusted its financial support for the villages from an average annual sum paid to all villages to a situation in which much of the funding was concentrated on a small number of best-kept 'pilot' villages. If Xulian was chosen, it would bring huge public investment and significantly change the village; if not, even less funding than before would be available to the village. Shen spared no efforts to advocate this golden opportunity:

"Our village has a good location of transportation, but we never had such opportunity of investment and development. ...it's once in a lifetime. Why don't we apply (and fight for it)?” (Shen, female, village Secretary)

After several meetings at which Shen stressed the soundness of her ideas, the village decided to apply. However, they had to show their capability and potential to qualify for the pilot Beautiful Village Construction funding. At that time there was a top down government policy of dismantling illegal housing in rural areas, which was called "Construction of Non-illegal Building Village" ( Wu Wei Cun) at Qingpu. Even though, in 
terms of qualifying for the funding, it was not necessary to be completely successful in removing the illegal buildings, Xulian Village treated it as an opportunity to show their capability and potential in the "Beautiful Village Construction", as well as a chance to change the environment and landscape of the village, as the illegal housing were always not taken care of and dumped with kinds of dirty and messy things.

Some villagers - mainly those who had built the illegal buildings - did not agree with this action. It has been widely reported elsewhere in China that there was forced dismantling, or the collective was blackmailed in order to meet the top down requirement, both of which subsequently leading to the back and forth of illegal building phenomenon. Shen understood well that without village level consensus it would be impossible to resolve the problem successfully, but instead might turn out to be a desperate failure - in terms of the buildings and the opportunity to secure the additional funding. As the leader she adopted a strategy that had usually been ignored by previous village leaders, which was to establish the efficacy of the proposed collective action by mobilizing the old party members as a core group which could provide a legitimate channel through which connect the village cadres and villagers.

\subsection{Developing trust in the leadership}

Many of the old party members felt intensely disappointed about the state of the village, particularly when they thought back to the Collective Economy era and the way in which the whole village had shared a strong and common vision. Shen tried hard to convince and mobilized the elderly Party members by suggesting to them that they could help foster a new vision of a beautiful and well maintained village. The first step was to return their power to them by making use of the Yi-Shi-Hui approach to discussion and shared decision making with respect to village public affairs. Shen also re-established regular meetings for Party members and for village cadres. Both meetings were designed to promote communication, discussion and consensus building. By doing this, Shen reassured them that the decision making process would be transparent, institutionalized and would involve their participation. This led one of the Party members to comment:

"Yi-Shi-Hui of Party Members used to be (the former Secretary's) own people. They were relatives, and rarely organized meetings... (Now, if) using money (for public affairs), no matter how much it was, even buying an air conditioner (for the community activity room), it should be discussed in Yi-Shi-Hui. (The village) stopped and forbade dumping of chamber pots, (this) should also be approved (by Yi-Shi-Hui)." (Shen, male, elderly Party member)

Another member of the Party also commented on how much the situation had changed:

“(The new Secretary required the) Party Members' Plenary Meetings to be held (at least) twice a month; Party Group Meetings (at least) once a month... Everything was able to be spoken out openly; not hidden in the heart." (Xu D, male, elderly Party members)

Once the new meeting structure was in place, the next step was to enforce the working discipline of the village cadres. In the past villagers complained frequently about the dysfunctional village cadres. They had a decent wage compared with normal villagers, but it was difficult to find them even during the working day. They 
were elected to represent the villagers but seldom talked with or visited them. Shen enforced the discipline strictly, such that nobody was allowed to be late or to leave early, and she took the initiative to work as usual during weekends. For example, they organized a volunteering village service of Party members and village cadres (such as picking garbage, cutting wild grass at the roadsides) every Saturday. The changes were obvious and welcomed by villagers, which also contributed to the villagers gaining trust in the leaders. The final step was to help the Party members and villagers learn about the Government policies that impacted on the village, as a means of illustrating the potential benefits for the village as a whole. The village representatives were also encouraged to visit other pilot villages to investigate and learn by themselves.

Through the pro-activity of the village Secretary as well as a string of meetings to learn and negotiate, mutual recognition between Party members, cadres and the village Secretary was significantly improved. Through various symposia, Party Members Meetings, study sessions, and mutual communications, elderly Party members were fully mobilized, realizing that the new Secretary really intended to initiate a common vision that would revitalize the village.

\subsection{Mobilizing the villagers to overcome the free-rider problem}

Mobilizing the Party members did not guarantee that the villagers would join in. In Ostrom's (2000) terms, it could be said that, at that time, the villagers did not have a common vision of the village as their desired homeland, and were thus not inclined to incur cost in improving it. Since dismantling the illegal buildings had already incurred costs for some of the villagers, ensuring the participation of the villagers was very difficult. The question for Shen was thus how to mobilize all the villagers to participate, and in the time available to bid for the additional funding. It turned out that the elderly Party members who had first been mobilized by the Secretary played an outstanding role in encouraging the villagers to get involved, even though it meant incurring personal cost.

The first stage in Shen's process involved continuous publicity and mobilization. Although all kinds of village group events were organized by the village committee and the Party Branch, most villagers still did not believe in the efficacy of the open negotiation on the implementation, and initially hesitated to participate. The Secretary realized that frequent personal visits to most households was necessary, but she could not cover them all, and was not an appropriate person in some cases. Consequently, the 73 elderly Party members volunteered to act as the 'bridge and platform' between the village cadres and villagers. The policy concepts of the village leaders were passed to the villagers and the villagers' feedback was returned to the village cadres, via the elderly Party members. This process continued until a modified plan emerged which was accepted by most people.

Following the success of this stage, the next was to lead by example and demonstrate what was required. As dismantling the illegal buildings meant considerable economic loss to many villagers, it was very difficult for the villagers to accept it when there was no compensation. Relying on early effective communication and an implementation guideline that "the Secretary took the lead, the Party members and the cadres followed first: NO exceptions" to remove their own illegal buildings, it still took the whole village more than a year to successfully complete this difficult task. 
"I am a Party member...I was the first one to remove the unauthorized part of my house." (Shen, male, elderly Party member)

"Her (village Secretary) father had a pig shed... In fact, it was approved officially and not part of the illegal buildings. However, he was also persuaded (by the Secretary) to have it dismantled." (Xu D., male, elderly Party members)

Once removal of the illegal structures had started, the third stage in the process was to conciliate with those who had suffered economic losses, and to monitor the situation to ensure that the structures were not replaced at a later date. There were some key villagers who were particularly reluctant to lose their private benefits, and they refused to negotiate with the village cadres. If the guideline of "no exception" were not seen to apply to them, the whole collective process would be violated, and more conflicts would be ignited from the other, compliant, villagers. The elderly Party members thus took up the responsibility of persuading the reluctant villagers. Traditional community mechanisms were applied. For example, the elderly Party members used all kinds of relationship networks (renqing) to add to the persuasion, including relatives, friends and teachers. In the end, all the villagers accepted that by demolishing their illegal structures they were contributing to public benefit for all members of the village.

"There was a household at the south of the village. The Secretary and elderly Party members went to negotiate fifteen times. One householder even scolded the Secretary with a finger on her nose. We had to seek help from their relatives and friends. Finally, it was settled. The Secretary told us to keep in mind that there was a lock on the heart for everybody and you might not be able to unlock it. Never give up. Just find the right person who could do it." (Shen, male, elderly Party members)

With the active leadership of the elderly Party members and the insistence that there should be no free riders, the villagers' perceptions of the village collectiveness and the village cadres changed significantly. They experienced the changes personally: it was recognized that the village cadres were making efforts that went beyond their personal interests. At the same time, Xulian Village also fully recognized the special role of the elderly Party members, and formally acknowledged the Party drop-in service stations as a key platform connecting villagers and the collective.

Although dismantling illegal buildings helped improve the landscape and the quality of the public spaces, there remained many other challenges for the wider community, such as the long term management of the village environment. In particular, the residents would see their losses as ongoing, due to the loss of income from keeping poultry and livestock. Both the village cadres and the villagers were confident that those problems could eventually be resolved with new funds from the government for improved village management. The villagers' participation increased via all kinds of opportunities offered by the village committee and Party branch, such as a number of official villagers' symposia leading to direct calls for action. Increased use of the drop-in service stations resulted in many suggestions arising concerning the recreation club, public facilities, riverside greening and other public benefits. After several rounds of negotiations, the entire village 
successfully created the long-term Beautiful Village management Plan. Very importantly village rules were also agreed and implemented.

Ongoing monitoring is a core element in long-term management of the Beautiful Village Plan. Due to the scattered distribution of households, there would always be potential low efficiency and high cost challenges in the government-led model or the market-based model to manage monitoring and enforcement. In Xulian Village, the nine elderly Party members who oversaw the three drop-in service stations volunteered to undertake daily inspections and monitoring, with a camera and patrol records provided by the collective. The results were noted daily and were made available for public viewing. Such frequent patrolling not only helped with the enforcement of the village plan, but also reinforced to the villagers the general importance of the village rules. In addition, other local problems were identified and resolved in their infancy by the elderly Party members. However, the village did not actually have to bear any cost, and the elderly Party members never complained about a lack of compensation for their efforts. They knew that the monitoring sometimes offended others (and thus they were losing 'standing' in the community), but they persisted because they believed it was the right thing to do:

"The elderly cadres and the elderly Party members were relatively honest and prestigious. They came to your house time after time and you could really feel embarrassed. Eventually, villagers would listen to you.... For some stubborn villagers, sometimes we chose to persuade their friends and relatives first, and then they would join in. Those Party members or cadres that had connections with the (stubborn) villagers were also sought out, to talk to them." (Shen, male, village cadre)

"An elderly woman at the bridgehead built a (illegal) fence. At first, she would not listen to anything we had to say. Then (old Party member) persuaded her husband, and he successfully convinced his wife. It took three visits (coming to house) to solve the problem. There were individuals that required five visits.... To tell the truth, I am offending others all the time (and losing my renqing)." (Xu H., male, elderly Party members)

The role of the Party members drop-in service stations in acting as 'bridge and platform' between the villagers and the leaders was well received. There was no doubt that many aspects of the construction and management of the Beautiful Village Plan, no matter big or small, had impacts on most villagers. Some villagers had some suggestions or feedback, but they were reluctant to go to the village committee as it was inconvenient; with a drop-in service station nearby they could simply talk to the person on duty, and the elderly Party members would do the rest. The Party members were responsible for receiving and recording various problems, and for doing whatever they could to solve them; unresolved issues would be passed to the cadres. In addition, the village Secretary and the village cadres would visit the drop-in service stations every Saturday to help solve problems, and to learn about the various ideas and needs of the villagers. For example, some villagers complained that the requirement that frames for growing vegetables should be no higher than $1 \mathrm{~m}$ caused inconvenience to their daily life because they could not cultivate loofah, cucumber and other crops. However, it was felt that the riverside - where most of the vegetables were grown - should appear well managed instead 
of being encroached by the vegetables. Others suggested that the village collective should strive for more economic projects and opportunities as the village became increasingly attractive. All such issues and ideas were submitted to the Village Committee Meetings through the drop-in service stations, with specific solutions proposed. For instance, after several consultations between the village cadres and villagers, it was decided to set aside a special area from the village collective land for villagers to grow tall vegetables, and that those villagers had to pay a rent for this land.

Based on their achievement, it was envisaged that the village would be qualified for the governmental rewards for good performance (yi jiang dai bu), which enabled the Village to provide subsidies for individual villagers. Each villager signed a contract with the collective agreeing to abide by the local rules, and those who complied would get a subsidy of 120 yuan per capita annually, depending on the rewards the village could earn from the township government's inspections. It transpired that the subsidy was enough to cover losses incurred from reduced levels of poultry raising and vegetable planting.

With these joint efforts, Xulian Village's long-term management proved successful, and was acknowledged by the villagers as well as the district and town governments. The village was awarded the prize of 'Beautiful Village of Shanghai in 2018'. In terms of the rural environment, the approach not only solved problems such as unsanitary dumping of wastes, but also achieved the control of livestock and poultry farming and of emptying chamber pots in the river. Rivers, roads and farmland were kept clean and tidy, becoming an integral part of the village landscape.

\section{“DongZhuang Village in Liantang Town became Beautiful Village earlier, but its environment was not as good as ours... (Xulian Village) has laid solid foundations and we want to be the national level (Beautiful Village winner)." (Xu H., male, elderly Party members)}

A particular advantage of collective action in this long-term village management was cost-efficiency. According to data from the village committee, before the collective action, the government invested about 300,000 RMB each year, hiring as many as 21 villagers to clean roads and rivers, but the results were unsatisfactory. However, under the collective action, the environment was greatly improved and it cost only 200,000 RMB for the village cleaners. The household subsidy of 120 RMB per capita for cooperative villagers was funded from governmental rewards only if the whole village had passed the inspection with a high enough score annually. Xulian Village managed to obtain the top-level rewards of 800,000 RMB. Compared with top down governance model, the collective action model of Xulian Village has a sharply reduced cost and a high level of performance. In addition, most of the financial benefits were captured directly by the villagers, rather than external contractors, which caused further spillover effects in villager behaviors:

\section{"In the past, the village carried out 1 or 2 cleanings every month. Although there were villagers hired for cleaning, the phenomenon of littering after the sweep was still common...Now it's rarely seen." (Shen, male, elderly Party member)}

Finally, through this responsibility-driven collective action, the relationships between villagers were improved, and the community governance mechanisms have been reshaped and given a new life. With the influence of the elderly Party members as the 'platform and bridge', the good relationships between the village cadres and 
the villagers has also been improved, a sense of community has been fostered, and the common goal of building a beautiful homeland has materialized:

"Before, villagers quarreled with village cadres frequently. Now it's gone. The villagers and the village cadres stay more harmonious... I am also willing to cooperate and make my own contribution. (For example) I noticed there was garbage in the roadside, and the village cadres were not available at that time. I just called the tractor to cart it away (at my own expense)." (Xu Y., male, founder of rural cooperatives)

\section{Discussion}

Even though collective action is considered effective for solving rural community affairs, most studies are of scenarios capable of generating private interests from the collective problems. Rural environmental management, as a type of regional public good, is more concerned with the sharing of responsibilities within the community. Our findings from Xulian village demonstrate how such collective action might be initiated, mobilized and maintained in the long term in a Chinese village, even under the context of rapid rural depopulation. The findings offer new insights in how three aspects - the use of strong leadership, an appropriate strategy for organizing, and identification of a suitable core group - can facilitate collective action to function well in the distribution of responsibilities. That collective action can function successfully in this scenario is a new finding, as is the finding that all three elements appear to be essential components in achieving the action. .

The concept of leadership is receiving increasing attention in evolutionary models of collective action (Hooper et al., 2010; Price and Van Vugt, 2014), but it remains based on the assumption that there will be personal benefits for both the leaders and followers, acting as incentives. However, these ideas have not yet been supported by empirical studies (Glowacki and von Rueden, 2015). In our case study it is not so obvious that the good leadership demonstrated by the new Party Secretary was motivated by the prospect of personal gain. It is certainly the case that the Secretary was native to the village and understood what mattered to different types of villagers; this allowed her to demonstrate strong leadership not by increasing her power, but rather by returning power to the collective village processes of decision-making, and making public affairs transparent. In addition, she showed her enthusiasm for the community, by personally pioneering whatever she could:

"The Secretary is a decent person. She arrives at work by 7:30 am, and continues working at village on Saturday and Sunday. In almost everything she took the lead, and the other village cadres followed." (Xu D, male, elderly Party member)

"I doubt whether we might have achieved anything without the Secretary. ... The village committee became much more united, and determined to change the village... I was impressed and volunteered to help. ... If she leaves in the future, I doubt others would be (as) competent." (Shen, male, elderly Party member)

There is little evidence that the incentive for the Secretary was based on her personal economic interests, but rather on the common will to change the unpleasant condition of the village. She did ultimately acquire a 
higher standing in the village due to the success of the action, which she could not have anticipated when she became Secretary. As with any public or Party official, there is almost certainly an additional personal motive connected with being recognized (and perhaps rewarded) for doing a good job. This is not something that we explored with the Secretary, but anyone taking on public office must do so in the knowledge that their performance will be monitored and recorded.

Our case indicates that in the context of responsibility distribution, the mobilization strategy was critical and was fundamentally different from mobilization strategies commonly used in the more usual cases where a distribution of benefits is anticipated. It was impossible for the Secretary herself to pioneer everything and she could not bridge the gap to reach out to all the villagers. In addressing this the Secretary first mobilized the 73 Party members, and then opened channels for them to have more influence in decision-making, distributing her power and facilitating them to become organized in different roles for publicity and mobilization, demonstration, conciliation and monitoring. Her organizing strategy was consistent with Lievegoed's theory of organizational development (Lievegoed, 1980; [Instruction: please replace "Glasl;" with "Glasl and".]Glasl; Lievegoed, 1994) in which the initial centralization of power and action (known as pioneering) is replaced by a more bureaucratic structure in which roles are differentiated and power is delegated.

The identification of the core group of nine followers who served as the foundation for the differentiated strategy of the collective, was particularly effective in distributing responsibilities among all villagers. In hindsight, these elderly Party members who remained in the village proved to be the right core group for the situation, not least because they had much experience of, and strong connections with, the collective. It also became clear that they maintained a strong feeling for their native village and had less concern for personal economic gains.

Such a phenomenon has been identified in many rural areas in China (Liu and Ravenscroft, 2017), where reputable elders (usually Party members) have prestige or 'standing' in the village, and are thus capable of bridging different social groups to provide a platform for all kinds of negotiations and compromise. These elders are usually familiar with inherited local knowledges and social networks, allowing them the agency to use these knowledges in undertaking their functions. In Xulian Village, for example, when some villagers refused to cooperate with the village rules, the elderly Party members and village cadres were able to deploy a range of tactics to negotiate a solution. In the language of the local culture, this was understood as the elderly Party members and the village cadres respecting and caring about the villagers, which bound them under a localized relation (renqing) pressure which is difficult to reject. Thus, much of the management cost was internalized and would not hinder the collective action with any long term financial burden.

Responsibility-driven collective action is clearly much more difficult to achieve than the more usual case of benefits distribution. It does not mean that such collective action is without benefit for the villagers. The difference is that the benefits - if they materialize - are available to all regardless of their participation, and only become available when the distribution of responsibilities has been successfully undertaken, as observed by one villager:

"For sure the environment is much better than before. All the houses have been polished white as well. The roads are well built. But we farmer do not benefit. No 
In the Xulian case, the direct benefits for the villagers included improved living conditions and the related health and happiness effects. In addition, as the quality of the environment improved, those who had left to work elsewhere have returned more frequently, which has become an important source of personal benefit for their families. And, of course, the village received the enhanced government grant which, according to the Party Secretary, covered the financial loss that some villagers had endured when they removed their buildings or ceased farming. . However, not all the villagers saw it in this way:

"The village looks better. There used to be many messy stuffs everywhere, now all are gone. ...However, the villagers gain no actual benefits. For example, chickens and ducks are only allowed to be raised inside houses, but those houses were all dismantled (as illegal buildings) ... Last year we are subsided at $¥ 10$ per month. What could we eat with that much money!" (an old couple of 60 years old, nonparty members)

Beyond the undoubted environmental benefits, the clean and tidy village is now attractive to tourists and investors, and is generating development opportunities for at least some of the villagers. Thus it appears to be the case that the distribution of responsibilities in Xulian Village generated a number of indirect benefits for both the leader and the participants. The capacity of the village to capitalize on these benefits will determine the sustainability of the Village Plan in the long term.

The model of responsibility-driven collective action that we have found in Xulian Village has elements which seem widely applicable to other villages in China, and around the world. However, the case study also reveals an important limitation that could affect its utility on a wider global scale: the key role played by the elderly Party members (see Kan, 2016 for a review of the function of village committees). Serious 'hollowing out' of many villages in China (Long et al., 2011) has made those who remain - usually the elderly - an important force in village restructuring. But the size and vitality of this group will inevitably decline as time goes by. It is not at all clear how they will be replaced, although some studies have found that other social groups, such as the 'left-behind' village women can be equally effective in fostering collective action (Du et al., 2019).

\section{Conclusion}

Collective action has been widely discussed with respect to the management of common pool resources, but usually in the context of the distribution of resources rather than responsibilities. In this paper we have analyzed an alternative case in rural China in which the principal concern has been how to distribute the costs of improving the infrastructure and environment of a village that no longer had access to public funding. In undertaking the study, we posed the research question: 'To what extent can a new form of responsibility-driven collective action provide a solution to the under-provision of public goods? Our findings indicate that it is possible to conceive of a situation in which the collective, as a whole, takes responsibility for the provision of public goods, even when this has a cost that is unlikely to be compensated as a result of the action. Unlike the case of benefit distribution in which there is an individual incentive to act collectively, the responsibilitydriven collective action in our case was fostered by strong leadership and a 'bridge' to the villagers provided 
by a core group of elders who, between them, motivated and mobilized the villagers into collective action and, where necessary, enforced compliance on those villagers who were less inclined to participate.

Our findings demonstrate that the principles of collective action are indeed relevant to scenarios featuring the distributions of responsibilities rather than benefits. Our findings also confirm literature suggesting that leadership is key (Glowacki and Von Rueden, 2015), but differ in that the private gains to the leader are less obvious and immediate than is generally considered to be a condition for action. Indeed, while part of her motivation may have involved currying favour with the Party, it is clear from the case study that the Secretary was strongly motivated by a wish to improve the village's public realm. The findings further confirm literature on the importance of organizing collective action (Hooper et al., 2010; Kan, 2016), to the extent that it does not happen spontaneously, and adds to existing work on motivating and mobilizing the collective (Li et al., 2016; Du et al., 2019). Good leadership here was not about assembling and concentrating power, but about redistributing it to the core group and thence to the wider village. This empowered the core group to encourage the villagers to act collectively to achieve lasting change through effective and efficient enforcement of individual responsibilities. This led to stable and long-term improvement in the quality of the village environment and its management.

Our findings on the nature and operation of responsibility-driven collective action are likely to be transferable to many of the villages in China that are experiencing similar social and environmental challenges. However, when looking to the future, other types of 'bridging' group will need to be developed to replace the elderly Party members, who will not be around forever. More generally, our articulation of responsibility-driven collective action as a new and under-researched form of community organization suggests to us that there is a potentially rich theme of work to be developed that has applicability beyond China. Indeed, as many national governments seek to withdraw from their financial commitments to the local state, many small and remote communities across the World may be faced with the imperative of fostering action for which there is no immediate pecuniary benefit to the individual. We believe that our case study of Xulian Village and the leadership qualities exhibited by Shen, its Party Secretary, offer new insights into how collective responsibilities may be mobilized in ways that lead to sustainable improvements in the environment and lives of rural communities, whether in China or beyond.

\section{CRediT authorship contribution statement}

Pingyang Liu: Conceptualization, Methodology, Writing - original draft. Ye Zhao: Investigation, Writing original draft. Neil Ravenscroft: Formal analysis, Writing - review \& editing. Marie K. Harder: Formal analysis, Writing - review \& editing.

\section{Acknowledgements}

We gratefully acknowledge the funding support from SH-POPSS (2019BGL035).

\section{Appendix A Supplementary data}

Supplementary data related to this article can be found at https://doi.org/10.1016/j.jrurstud.2020.02.008. 


\section{Uncited references}

Hodge, 2001; Nelson and Nelson, 2010; Ostrom, 2005.

\section{References}

(i) The corrections made in this section will be reviewed and approved by a journal production editor. The newly added/removed references and its citations will be reordered and rearranged by the production team.

Agrawal, A., 2001. Common property institutions and sustainable governance of resources. World Dev. 29, 1649-1672.

Agrawal, A., 2003. Sustainable governance of common-pool resources: context, methods, and politics. Annu. Rev. Anthropol. 32 (1), 243-262.

Anderson, C., Brown, C., 2010. The functions and dysfunctions of hierarchy. Res. Organ. Behav. 30, $55-89$.

Baldez, L., 2002. Why Women Protest: Women's Movements in Chile. Cambridge University Press, London.

Beard, V.A., Dasgupta, A., 2006. Collective action and community-driven development in rural and urban Indonesia. Urban Stud. 43, 1451-1468.

Bimber, B., Flanagin, A., Stohl, C., 2012. Collective Action in Organizations: Interaction and Engagement in an Era of Technological Change. Cambridge University Press.

Carr, P.J., Kefalas, M.J., 2009. Hollowing Out the Middle: the Rural Brain Drain and what it Means for America. Beacon Press, Boston.

Chan, M., 2016. Psychological antecedents and motivational models of collective action: examining the role of perceived effectiveness in political protest participation. Soc. Mov. Stud. 15, 305-321.

Coase, R.H., 1960. The problem of social cost. J. Law Econ. 3, 1-44.

Dietz, T., Ostrom, E., Stern, P.C., 2003. The struggle to govern the commons. Science 302, 1907-1912.

Du, Y., Ravenscroft, N., Wang, Y., Liu, P., 2019. Governance, gender and the appropriation of natural resources: a case study of 'left-behind' women's collective action in China. Soc. Nat. Resour. 32, 382399.

Fałkowski, J., Chlebicka, A., Łopaciuk-Gonczaryk, B., 2017. Social relationships and governing collaborative actions in rural areas: some evidence from agricultural producer groups in Poland. J. Rural Stud. 49, 104-116. 
Feuchtwang, S., 1998. What is a village?. In: Vermeer, E.B., Pieke, F.N., Woei, L.C. (Eds.), Cooperative and Collective in China's Rural Development: between State and Private Interests. M. E. Sharpe Inc, New York.

Ganz, M., 2002. What is organizing. Soc. Pol. 33 (1), 16-18.

Glasl, F., Lievegoed, B., 1994. Dynamische unternehmensentwicklung: grundlagen für nachhaltiges Change Management. Haupt Verlag, Bern.

Glowacki, L., Von Rueden, C., 2015. Leadership solves collective action problems in small-scale societies. Phil. Trans. Biol. Sci. 370, 20150010.

Hardin, G., 1968. The tragedy of the commons. Science 1243-1248.

Hodge, I., 2001. Beyond agri-environmental policy: towards an alternative model of rural environmental governance. Land Use Pol. 18, 99-111.

Hooper, P., Kaplan, H., Boone, J., 2010. A theory of leadership in human cooperative groups. J. Theor. Biol. 265, 633-646.

Ito, J., 2012. Collective action for local commons management in rural Yunnan, China: empirical evidence and hypotheses using evolutionary game theory. Land Econ. 88, 181-200.

Kan, K., 2016. The transformation of the village collective in urbanizing China: a historical institutional analysis. J. Rural Stud. 47, 588-600.

Kapoor, I., 2001. Towards participatory environmental management?. J. Environ. Manag. 63, 269-279.

Li, Y., Westlund, H., Zheng, X., Liu, Y., 2016. Bottom-up initiatives and revival in the face of rural decline: case studies from China and Sweden. J. Rural Stud. 47, 506-513.

Liu, P., Ravenscroft, N., 2016. Collective action in China's recent collective forestry property rights reform. Land Use Pol. 59, 402-411.

Liu, P., Ravenscroft, N., 2017. Collective action in implementing top-down land policy: the case of Chengdu, China. Land Use Pol. 65, 45-52.

Liu, P., Ravenscroft, N., Harder, M.K., Dai, X., 2016. The knowledge cultures of changing farming practices in a water town of the Southern Yangtze Valley, China. Agric. Hum. Val. 33, 291-304.

Liu, S., Xiong, X., 2018. China's rural institutions and governance since the beginning of the rural reform. China Econ. J. 11, 259-283.

Liu, Y., Li, Y., 2017. Revitalize the world's countryside. Nature 548 (7667), 275-277.

Lievegoed, B.C.J., 1980. The Developing Organization. Celestial Arts, Berkeley, CA. 
Long, H., Zou, J., Pykett, J., Li, Y., 2011. Analysis of rural transformation development in China since the turn of the new millennium. Appl. Geogr. 31, 1094-1105.

McCarthy, N., Kilic, T., 2015. The nexus between gender, collective action for public goods and agriculture: evidence from Malawi. Agric. Econ. 46 (3). 375-40.

Meinzen-Dick, R., Raju, K.V., Gulati, A., 2002. What affects organization and collective action for managing resources? Evidence from canal irrigation systems in India. World Dev. 30 (4), 649-666.

Nelson, L., Nelson, P.B., 2010. The global rural: gentrification and linked migration in the rural USA. Prog. Hum. Geogr. 1-19.

Olson, M., 1965. The Logic of Collective Action: Public Goods and the Theory of Groups. Harvard University Press, Cambridge, MA.

Orsi, L., De Noni, I., Corsi, S., Marchisio, L.V., 2017. The role of collective action in leveraging farmers' performances: lessons from sesame seed farmers' collaboration in eastern Chad. J. Rural Stud. $51,93-104$.

Ostrom, E., 1990. Governing the Commons: the Evolution of Institutions for Collective Action. Cambridge University Press, Cambridge, UK.

Ostrom, E., 2000. Collective action and the evolution of social norms. J. Econ. Perspect. 137-158.

Ostrom, E., 2002. Property-rights Regimes and Common Goods: a Complex Link. Common Goods: Reinventing European and International Governance. Rowman and Littlefield, Lanham, pp. 29-58.

Ostrom, E., 2005. Understanding Institutional Diversity. Princeton University Press, Princeton.

Pescosolido, A., 2001. Informal leaders and the development of group efficacy. Small Group Res. 32, 74-93.

Price, M., Van Vugt, M., 2014. The evolution of leader-follower reciprocity: the theory of service-forprestige. Front. Hum. Neurosci. 8, 363.

Sandler, T., 2015. Collective action: fifty years later. Publ. Choice 164, 195-216.

Saunders, F.P., Institutionen För Naturvetenskap, M.O.T., Södertörns, H., Miljövetenskap, 2014. The promise of common pool resource theory and the reality of commons projects. Int. J. Commons 8, 636656.

Takayama, T., Matsuda, H., Nakatani, T., 2018. The determinants of collective action in irrigation management systems: evidence from rural communities in Japan. Agric. Water Manag. 206, 113-123.

Thomas, E.F., McGarty, C., Mavor, K., 2016. Group interaction as the crucible of social identity formation: a glimpse at the foundations of social identities for collective action. Group Process. Intergr. Relat. 19 (2), 137-151. 
Tooby, J., Cosmides, L., Price, M., 2006. Cognitive adaptations for n-person exchange: the evolutionary roots of organizational behavior. Manag. Decis. Econ. 27, 103-129.

Van Zomeren, M., Postmes, T., Spears, R., 2008. Toward an integrative social identity model of collective action: a quantitative research synthesis of three socio-psychological perspectives. Psychol. Bull. 134, 504-535.

van Zomeren, M., Postmes, T., Spears, R., 2012. On conviction's collective consequences: integrating moral conviction with the social identity model of collective action. Br. J. Soc. Psychol. 51, 52-71.

Vedeld, T., 2000. Village politics: heterogeneity, leadership and collective action. J. Dev. Stud. 36, 105134.

Wang, Y., Liu, Y., Li, Y., Li, T., 2016. The spatio-temporal patterns of urban-rural development transformation in China since 1990. Habitat Int. 53, 178-187.

\section{Highlights}

- Community-based collective action has provided effective localized solution pathways for managing collective goods in scenarios associated with the distribution of costs, or responsibilities.

- Smart local leadership, an effective organizing strategy, and involvement of a suitable 'core group' was crucial.

- A responsibility-driven collective action on rural environmental management is described as well as the process, characteristics and influencing factors are analyzed.

\section{Appendix A Supplementary data}

The following is the supplementary data related to this article:

Multimedia Component 1

Multimedia component 1

alt-text: Multimedia component 1

\section{Queries and Answers}


Query: Your article is registered as a regular item and is being processed for inclusion in a regular issue of the journal. If this is NOT correct and your article belongs to a Special Issue/Collection please contact t.sankarappan@elsevier.com immediately prior to returning your corrections.

Answer: Yes

Query: Please confirm that given names and surnames have been identified correctly and are presented in the desired order and please carefully verify the spelling of all authors' names.

Answer: Yes

Query: Please confirm that the provided email “M.K.Harder@brighton.ac.uk” is the correct address for official communication, else provide an alternate e-mail address to replace the existing one, because private e-mail addresses should not be used in articles as the address for communication.

Answer: This is the correct email for official communication.

Query: References “Li et al., 2011; Persson and Prowse, 2017; Sultanaa and Abeyasekera, 2008; Saab et al., 2015" are cited in the text but not provided in the reference list. Please provide them in the reference list or delete these citations from the text.

\section{Answer:}

Please delete "Li et al., 2011" in the text, and add the following references in the reference list.

"Persson, J., Prowse, M., 2017. Collective action on forest governance: An institutional analysis of the Cambodian community forest system. Forest Policy and Economics 83, 70-79.

Sultana, P., Abeyasekera, S., 2008. Effectiveness of participatory planning for community management of fisheries in Bangladesh. Journal of environmental management 86, 201-213.

Saab, R., Tausch, N., Spears, R., Cheung, W.Y., 2015. Acting in solidarity: Testing an extended dual pathway model of collective action by bystander group members. British Journal of Social Psychology 54, 539-560."

Query: Have we correctly interpreted the following funding source(s) you cited in your article: SH-POPSS?

Answer: Please replace the whole acknowledgements with the following:

"We thanked anonymous reviewers for their insightful comments, and gratefully acknowledge the funding support from Shanghai Municipal Research Foundation For Philosophy And Social Science (2019BGL035)."

Query: Uncited references: This section comprises references that occur in the reference list but not in the body of the text. Please position each reference in the text or, alternatively, delete it. Any reference not dealt with will be retained in this section. Thank you.

Answer: Please deletle these references in the text. 
Query: Highlights should only consist of " 125 " characters per bullet point, including spaces. The highlights provided are too long; please edit them to meet the requirement.

\section{Answer:}

Please replace the highlights with the following one:

"Community-based collective action has provided effective localized solution pathways for managing collective goods.

Smart local leadership, an effective organizing strategy, and involvement of a suitable core group was crucial.

A responsibility-driven collective action on rural environmental management is described and analyzed." 